"This is the peer reviewed version of the following article: Gallagher, A. (2017). "Growing pains? Change in the New Zealand childcare market 2006-2016." New Zealand Geographer 73(1): 15-24., which has been published in final form at https://doi.org/10.1111/nzg.12147. This article may be used for non-commercial purposes in accordance with Wiley Terms and Conditions for Use of Self-Archived Versions."

\title{
Growing Pains? Change in the Childcare Market 2006-2016
}

Paper accepted to The New Zealand Geographer.

Publication in progress

\section{$\underline{\text { Abstract }}$}

There has been a significant growth in childcare in New Zealand since 2006. Shaped by debates in geography, social policy and education around the marketization of childcare, this paper will make some key observations about the childcare market in NZ, and examine how this has changed with the introduction of the 20 hours ece scheme in 2007. In doing so I will illustrate how the landscape of childcare has changed in favour of a burgeoning private sector, and consider the recent impetus for corporatisation. Finally I will examine the discourse of parental 'choice' which pervades policy discussions around ece in New Zealand and how this plays out in the face of an expanding priva te for-profit sector.

The significant rise in employment rates of mothers has shifted the 'burden' of childcare' from the reproductive, private sphere of the home to the productive economy, as it is increasingly rendered into a commodity for sale. Today, there are more young children than ever in formalised childcare in New Zealand. In 2016, 95\% of three and four year olds were in some form of extra familial care, with the majority in educational care (Ministry of Education, 2016). Yet meeting the burgeoning demand for childcare poses a vexing problem for liberal governments and their policy communities, where responsibility for childcare has been assigned to the domain of the family (Esping-Andersen, 2002; McDowell, et al 2005). Indeed NZ is not alone in facing this issue. On the one hand it is deemed to be ideologically unpalatable in the current political moment to instigate a state provided system to meet the needs of parents and children, as markets are being positioned as the preferred means of delivering social services (Clarke, 2004). On the other, childcare is being enveloped into a range of new policy agendas not only for employment 'activation' but also around the long term educational outcomes of young children, and so is becoming increasingly important for government (Mahon \& Michel, 2002). Consequently we are witnessing the emergence of new market based 'fixes' whereby the state is attempting to both foster the market and shape its development through market interventions. As Stephen Ball has observed with regards to education, "changes (are) taking place at the nexus between regulation and midwifery, that is the role of the state in setting limits to the market while at the same time creating conditions within which the market can flourish and expand (2012:17)".

Feminist and social geographers have long had an interest in the politics, ethics and delivery of childcare. Within this work much research has been focussed at the local and national level, where the discrepancies between policy and delivery are most evident (Mahon 2005; England, 1996), where the challenges of cost and distance are apparent (Halliday \& Little, 2001; Van Ham \& Mulder, 2005) and where the gender and class inequities in delivering care becomes visible (McDowell, et al., 2005; Pratt, 2003). Despite the strength of this disciplinary engagement, there has been limited analysis of the recent politics of change within childcare markets, with much research focussing on the implications of the commodification of care labour for those working in and using childcare 
(Gallagher 2013; Pratt xx; ...). That said, recent work outside of geography, located in social policy and education, has sought to trace the contours of childcare markets, particularly in countries where there has been an increasing reliance on private, for profit provision (Brennan, Cass, Himmelweit, \& Szebehely, 2012; Lloyd \& Penn, 2013). In countries like Australia, the UK, Canada and New Zealand, there has been a large scale move towards market mechanisms in driving and shaping the childcare market. In neoliberal welfare systems where workforce participation of mothers is increasingly sought after, placing your child in care during the working day is viewed as the best means of mitigating long term social disadvantage (refs), thus removing the element of parental 'choice' as to care for your child at home or not (refs). To facilitate this social and economic policy agenda, demand side subsidies (like the 20 hours ECE in New Zealand) along with other forms of supply side intervention (such as the use of tax credits in the UK (refs) have played a large part in reshaping the landscape of childcare, in lieu of a publically provided service and have also been a crucial aspect in encouraging families to use formalised childcare services.

Critics of this trend have identified some major problems as a result of the growth of for profit childcare (Penn, 2011). Evidence from Australia and the Netherlands have suggested that demand side subsidies, when made available to both community and private providers, have disproportionally favoured the private sector, which has tended to grow exponentially in response (Plantenga, 2012b; Sumsion, 2006). They suggest that this poses a problem in terms of equity of provision, as private providers tend to locate in wealthier communities, where the participation rates and overall fees can be higher. Such cherry-picking of locations has produced a highly patchy landscape of provision. Secondly the reliance on private providers is seen to directly mitigate the desire to improve quality and professionalization in the sector, as wages are generally lower in for profit services and the chances for upskilling significantly less than in community based services (May \& Mitchell, 2009). Lastly, the unfettered expansion of the market, driven by private providers, has been shown to create inherent instability in the sector. The reliance on generating a profit and in many cases being accountable to shareholders, means that any drop in the market has significant detrimental effects for an increasingly large part of the sector. This was spectacularly demonstrated with the collapse of $A B C$ learning in 2008 , which cost the Australian government $\$ 22$ million $A U$ to keep services solvent until a new owner could be found (Brennan, 2007 ; Newbury \& Brennan, 2013; Sumsion, 2006).

Shaped by these debates in geography, social policy and education around the marketization of childcare, this paper will make some key observations about the childcare market in NZ, and consider how this has changed with the introduction of the 20 hours ece scheme in 2007. In doing so I will examine how the landscape of childcare has changed in favour of a burgeoning private sector, and consider the recent impetus for corporatisation. Finally I will examine the discourse of parental 'choice' which pervades policy discussions around ece in New Zealand and how this plays out in the face of an expanding private for-profit sector.

\section{ECE and the introduction of the ' 20 hours Free' scheme}

New Zealand's government has not traditionally had a strong role in the delivery of childcare, much like other countries which can be classified as 'liberal' in their welfare orientation (Esping-Andersen, 1990). Rather, a mixed economy of care has been in place, where family, state, not for profit and for profit providers have played a part. However, since the late 1990s, the government has sought a 
more interventionist approach in line with the changing place of early education within policy for young children (Mitchell, 2013). Indeed, the introduction of Te Whāriki (1993), a bicultural curriculum from birth to school age, represented a leading stance by NZ in early education and care (Lee, et al. 2012). Part of this interventionist approach was to encourage greater emphasis on regulation and training in the sector. Under Labour, the level of trained teachers per service was set to be increased to $100 \%$ by 2012 . As Mitchell (2013) has suggested, funding to support this progressive initiative went from approximately \$350k in 2002 to almost $\$ 1.2$ million in 2010 and was primarily channelled into grants, scholarships and allowances to early education teachers and students. However, more recently, and under pressure from the private sector in relation to the anticipated inflation of salaries in line with qualifications, the subsequent National government has

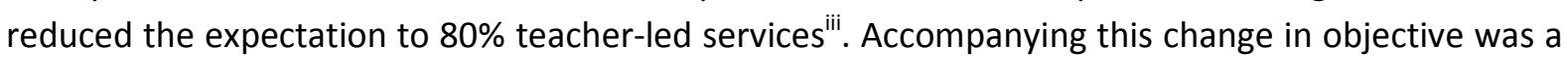
significant cut in the funding bands available to services (the $100 \%$ band was no longer funded and the $80 \%$ band was reduced), meaning that services who had upskilled to that level now found themselves having to recoup the extra funding from elsewhere to cover the cost of salaries (often through parental fees (Powley, 2013).

Increased emphasis on participation rates of children in ECE was the impetus for the 20 'free' ECE ${ }^{\text {iv }}$ scheme, introduced by the labour-led government in 2007. The current government has taken on that ambition and set a lofty target of $98 \%$ of children by 2016 to have experienced some form of early education by the time they start school, as part of its Better Public Services Programme (New Zealand Government, 2011). This has marked an important step in reconceptualising childcare as not just a private, family responsibility and offered funding to families of all 3 and 4 year olds up to the level of 20 hours per week. Originally only intended to be available for community providers, a strong lobby from parents who felt they were being disadvantaged by having their children in private sector care and potentially missing out on the subsidy, led to the expansion of the subsidy to all providers once they met the educational criteria set by government (May, 2013). Interestingly, as she suggests, the private sector (through the representative voice of the Early Childhood Council) urged its members not to engage with it as it was potentially a means of government 'interfering' into the work of private sector services. The decision to expand the scheme has marked a crucial turning point in the landscape of ECE in New Zealand as I will discuss in more detail in the next section. As participation was the driving motivation for the scheme costs to parents, as the primary barrier, needed to be reduced (Mitchell, 2013). Therefore a measure of its success has been how much parents have had their care bill reduced. In the first month of the scheme costs fell to parents by $34 \%$ nationwide (Statistics NZ 2007). The scheme initially represented the lowering of a considerable barrier for parents and has led to a significant increase in participation across income groups for 3 and 4 year olds (details will be outlined in the next section). Indeed, the Wellington, Otago and Canterbury regions have already met the $98 \%$ participation rate.

Currently there are seven types of educational care service in NZ (with nanny services not included). These include those categorised as teacher led services (Kindergartens, Steiner schools, ECE services and home based care) and Whanau led services (Playcentre, play groups, Kōhanga Reo). All private services are in either ECE centres or home based care. The remainder are community based. Although the terms community and private are used, the lines between the two are increasingly blurry, given they both access the same state subsidies. In an attempt to address some of the inequity in the market, the government has also introduced other smaller funding schemes which seek to help services in isolated communities and/or which have a significant proportion of their 
attending children from a lower socio-economic background. These are known as the Targeted Assistance for Participation (TAPS) funding and Equity funding. TAPS has capital funding which is available to both private and community providers, making NZ one of the few countries where capital expenditure for the private sector is funded by the government (Mitchell, 2015).

While a similar decile system has been in place to that used in the education sector more generally there has been some incentive, in line with the White Paper for Vulnerable Children (Ministry of Social Development., 2012), to move towards a more targeted system which identifies those who may be at risk of disadvantage at the preschool stage. Since 2014 all children starting ECE will be assigned a number in order to track them through the system and if they move between services, with information on student attendance (notably chronic absenteeism), along with other information about the facility now regularly uploaded to the new Early Learning Information System (ELI). Such a move is in keeping with a broader shift towards a 'social investment' approach, where more targeted and selective forms of intervention are deemed to generate the greatest social and economic returns (Jenson \& Saint-Martin, 2003). However, there have already been concerns raised as to the implications of how children are identified as 'at risk' and the potential for stigmatisation through the new tracking system (Haggerty \& Alcock, 2016). Another outcome of this change may be that services may no longer get extra funding based on their decile rating, but instead on the number of children identified as 'at risk' within their service (Jones \& Johnston, 2016). Funding of the sector is currently under review by the Ministry of Education at the time of writing.

\section{The changing geography of childcare in NZ}

This section is based on preliminary analysis of the Ministry of Educations 'Education Counts' dataset of childcare providers ${ }^{\mathrm{vi}}$. A publically available directory of services has been maintained since 2006, although more recent datasets have considerably more detail than the earlier versions, in part due to the new ELI system. Here it is possible to access information pertaining to things like service type, enrolments, and age and ethnicity of attending children. The availability of such detailed information was made possible by the significant amount of data which is now submitted as part of the compliance with funding, and as such is representative of the exponential growth in the level of accountability in the sector (see Osgood (2004) on the new politics of managerialism in childcare). The information used in this section relates to comparative analysis of the 2006 and 2016 datasets.

\begin{tabular}{|l|l|l|}
\hline Service Type & $\mathbf{2 0 0 6}$ & $\mathbf{2 0 1 6}$ \\
\hline Kindergarten & 620 & 653 \\
\hline Kōhanga Reo & 506 & 459 \\
\hline Playcentre & 486 & 430 \\
\hline ECE centres & 1856 & 2502 \\
\hline Home based care & 216 & 476 \\
\hline Total & $\mathbf{3 6 8 4}$ & $\mathbf{4 5 2 0}$ \\
\hline
\end{tabular}

Figure 1. Numbers of ECE facilities 2006 and 2016 
There are currently over four and a half thousand registered ECE providers in NZ, representing an increase of around 836 services since 2006. From figure 1, it is noted that the increase has been primarily in ECE centres and home based care, with ECE centres in particular increasing by $34 \%$ during this time. Indeed not only have the number of ECE centres increased, but the maximum capacity of these centres has also increased. In 2011 the cap on the number of children allowed under each centre licence went to 150 children over 2 and 75 under 2 (to replace limits of 50 and 25 respectively), leading to concerns by the Childforum and other advocacy groups of the potential of childcare 'supercentres'. As a result, there has been a significant increase in the average size of centres, notably a 40\% increase in the average size of private, full daycare between 2011 and 2016 (compared to $17 \%$ of community based services) (Childforum, 2016). The same study by Childforum estimated that in 2016 6\% of centres have 100 or more children compared to 2012 when no centre had more than 50 children. According to the national ECE census in 2014, only two service types had a greater number of enrolments compared with 2004; ECE centres and home based care. Ece centre enrolments have grown by $56 \%$ over the last ten years, while home-based services have grown by 93\% (although this seems high, its relative to the starting number, which was low) (Education Counts 2015).

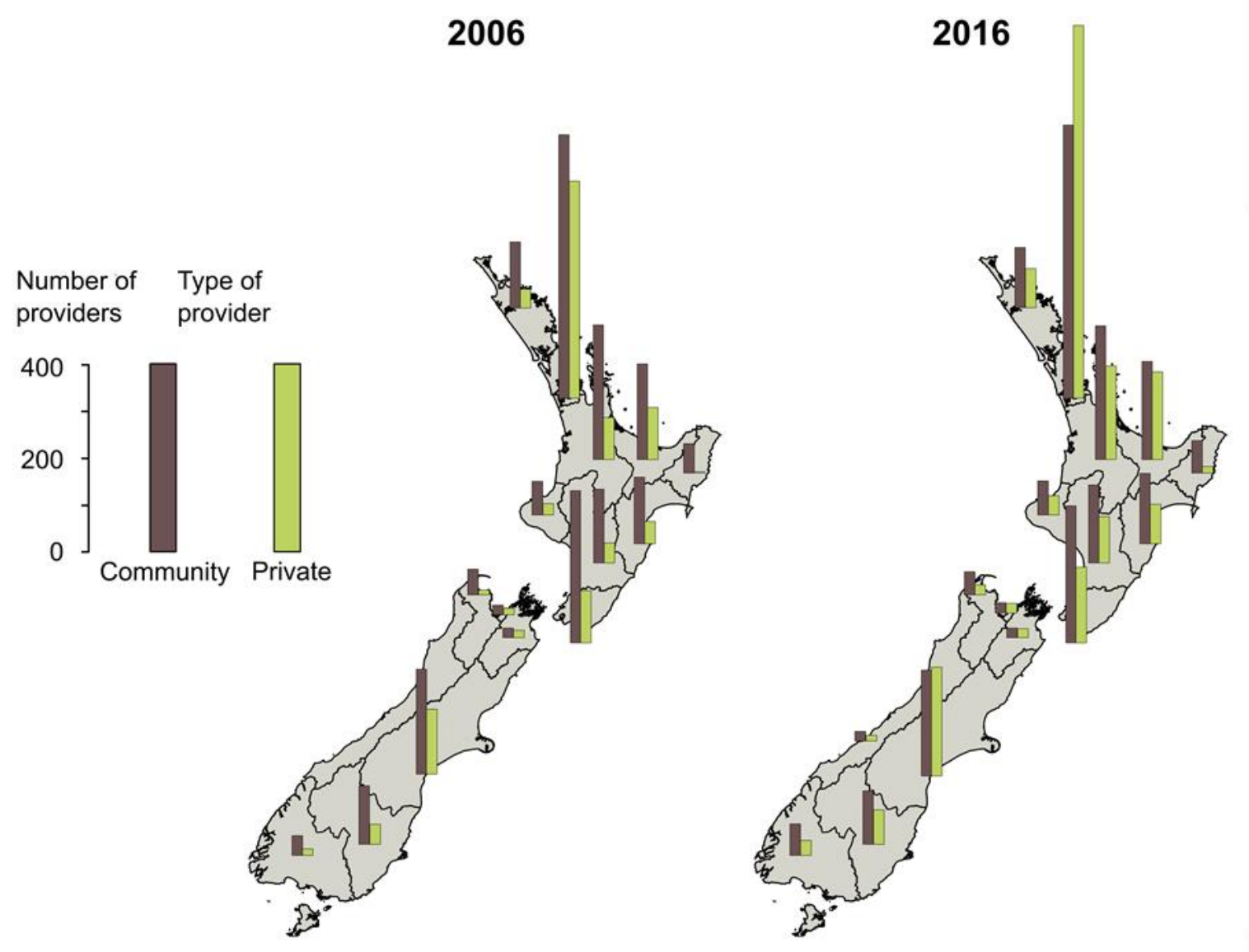

Figure 2: Change in private and community provision $2006-2016^{\text {vii }}$

One of the most striking features to be read from the data has been the growth of the private sector during this time period. All private provision operates from ECE centres or home based care (although there are also community providers working in these types of services). As figure 2 shows, 
the number of community based providers in most regions has stagnated while the private sector has increased, most significantly in regions with a major city. While most community based services have not increased by any considerable amount during the period between datasets, there have been two types which have had a notable decline in numbers of facilities. Playcentres have dropped in numbers and enrolments in many regions (Ministry of Education, 2016). As a parent led service, this drop is largely a reflection of the changing priorities of working households, whereby parents (primarily mothers) are returning to work and are less able to contribute as volunteers to such organisations. Consequently, staffing and running of playcentres is becoming difficult. The Kōhanga Reo have also had a downturn in their number of services with enrolments falling by a third between 2005 and 2011 (Ministry of Education, 2016). A Treaty of Waitangi Tribunal hearing in 2012 upheld the claim that the government, through its policies and regulations around early education, were unfairly undermining the work of the Kōhanga Reo, stating "The relationship between the Crown and Te Kōhanga Reo National Trust and kōhanga reo has deteriorated over the 2000 to 2011 period as a result of mismatch between government policy design with the aims and objectives of kōhanga reo". More specifically, the emphasis on early education (through the funding and regulations) sits at odds with the broader linguistic and cultural focus of the Kōhanga reo, such that they were often unable to meet the changing licencing requirements of the Ministry of Education. For many, this has been the reason that the number of services have dropped during the chosen time period (Mitchell, 2013). Moreover, Kōhanga Reo and playcentres were only included in the 20 hours ece scheme in 2010.

\section{Marketisation and growth of corporate childcare}

While the majority of private sector providers remain single owner-occupiers with anywhere between one and five services, childcare chains have begun to occupy an increasingly large share of the NZ childcare market. Mitchell estimated it to be $13 \%$ in 2012, but this has since increased through the emergence of a second large childcare corporate on the scene. The two main childcare chains currently in New Zealand are Beststart (formerly Kidicorp) and the Evolve Education Group. While Beststart initially floated on the stock exchange in 2003, its owner, the Wright family, removed it again in 2007 citing irreconcilable differences in trying to meet dividend expectations of shareholders and keep costs down for parents (Owen, 2007). As such Beststart aims to offer ece services in not only high income communities, as the general critique of private sector childcare tends to be, but to have a presence in lower income communities also. The other major corporate provider is the Evolve Education Group, which formed in 2014 on the back of a stock exchange IPO. Childcare chains like these have tended to purchase already existing services and amalgamate them into a particular brand, although sometimes they continue to operate under the existing name, rather than open new services in an already buoyant childcare market (as is the case of Beststart). Beststart took over the New Zealand branch of $A B C$ Learning when it went into liquidation in 2008 and now owns over 250 services nationwide and caters to 18,000 families annually (Beststart 2016). While their logo is the same, they operate under seven different names across the country, giving a regionally diversified face to the brand. Evolve have taken over an existing smaller childcare chain called Lollipops as well as establishing interests in home based care (notably Porse) and other childcare support industries (ECE Management). Currently they own just over 100 services nationwide. 
The growth of private, for profit childcare in NZ has been a marked trend since the introduction of the 20 hours free scheme in 2006. Indeed, following trends in other liberal contexts, it seems highly likely that the funding scheme has actually fostered this investment interest (Plantenga, 2012b). The governmental push to achieve $98 \%$ participation by 2016 is being read in as an incentive for corporate providers, offering a guarantee of further spending into the sector (see for example the investment strategy of Evolve Education 2016). Important questions are being asked about the proliferation of corporate childcare providers in response to government subsidies. The growth of demand side subsidies by governments internationally has fostered a unique business environment for investment into the childcare market (Scherer, 2009). As the Chairperson of ABC learning stated in 2008 before its collapse 'This is a business subsidised by government - how can it be unprofitable?" (Kruger, 2011). It is perhaps not surprising that in the current climate, a government subsidised business opportunity is one which is hard to pass up.

Moreover, we are witnessing the involvement of international investment and pension funds into the corporate childcare sector. The returns from centres are thus often intended for overseas shareholders, further deepening the tension between quality of care and profit making incentives (Sumsion, 2006). The creation of shareholder reports and other such forms of accountability has been a key part of the financialisation of the sector. All facets of the childcare sector are now anticipated to be made into assets with a value attached. (Newbury \& Brennan, 2013). This was made evident through the investigation into the collapse of $A B C$ Australia. As became apparent, their dramatic increase in value on paper was in large part due to intangible assets, like the childcare licences themselves, as the company sold off its rights to its capital assets in order to generate revenue to expand the business (fuelled by government subsidies). It sold and rented back its facilities at a fixed price in a peculiar financialisation arrangement. This model of operation even extended to the purchase and lease back of toys, in an effort to release capital to develop more centres (Herald, 2009).

Alongside childcare providers, there has been a proliferation of other childcare support industries over the last ten years. Special finance companies, such as Childcare Finance NZ, have emerged, tailored to the specific needs of ECE services and in particular the demand for bridging loans to meet the delay in the bulk funding payments. These payments come in four monthly instalments throughout the year, with $75 \%$ paid based on the enrolments over the past four months and then a $25 \%$ 'wash-up' when actual numbers are assessed. The pressure to meet the reporting demands for funding, particularly as centres increase enrolments as the licencing restrictions are lifted and services grow more complex in the kinds of services being offered, has led to the development of a range of specialised software packages for childcare providers. Packages such as Datacom and Inforcare offer cloud computing for the management of services and help keep track of student's attendance, payroll and so on. They also represent, as Jayne Osgood (2004) has cautioned, part of the increasing managerialism now embedded in the running of these facilities.

\section{The discourse of 'choice' and the role of the Parent-Consumer}

While ostensibly aimed at achieving higher levels of participation, ironically the 20 hours ece scheme, by being made available to both community and private providers, may have gone some way to exacerbating the inequities in the existing childcare market in NZ (Mitchell, 2015). There has been a strong correlation between the exponential growth of private, for profit, provision and the 
introduction of the government subsidy into the sector. As has been well established, private providers are much more likely to be found in higher income communities (Lloyd, 2013). Indeed ABC learning when it was in operation in NZ, admitted to actually targeting high income communities as part of its business strategy. What remains is a system whereby families in rural communities and smaller towns have much less choice in terms of the services they are accessing (see England, 1996 for a discussion of how these inequities play out). Although there are other forms of funding now available to try to offset these inequities, (Equity and TAPS funding), they are also made available to the private sector, and so their ability to actually offset these differences is limited (Mitchell, 2015).

The desire to increase participation of young children in ECE has become a strong policy agenda of the current National government (Mitchell et al., 2013). It is interesting to note that the discourse of parental choice within policy framings with regard to ece is not one of whether or not to place your child into care, but rather choice around which service to use. This is not solely a trend confined to New Zealand social policy. As Mcleavy (2011) has argued with regard to the UK, there have been strong incentives to encourage women, particularly mothers into employment while there children are at a preschool age as it is seem as a means of mitigating the long term effects of social disadvantage (see also McDowell ..). While this is encouraged for middle class and working class mothers, through the provisioning of incentives to lower the cost of childcare and therefore increase access, for women who are identified as high risk of social disadvantage (such as single mothers), the emphasis on (re)entering the workforce is less about the carrot and more the stick approach (refs). In New Zealand this was reinforced in 2011 with the Welfare Working Group report, the outcome of which has meant that single parents are required to place their child in ECE once it is three and women who have more children when they were in receipt of a benefit to be 'work ready' when their youngest turns one. Failure to place your child in ECE can result in a $50 \%$ cut to your benefit and potential 'intensified case management support' from MSD (Welfare Working Group, 2011). Thus for parents as beneficiaries with young children, ece in new Zealand is increasingly becoming a social obligation and marks an interesting extension in how responsibility for children is being reconceptualised in NZ (see Kingfisher, 2013 for a critique of welfare policy for single parents in NZ).

The success of the childcare market is predicated on the actions of parents as 'informed' consumers of care (Plantenga, 2012a). In theory, an imagined parent-consumer will exercise their agency in the market by choosing the service that best fits their needs. As Minister for Education, Hekia Parata, has suggested with regard to concerns about the creeping costs of childcare, in the current market "parents have choices. They need to take control, shop around" (Powley, 2013). It is understood that through exercising this agency, parents can work to keep costs down and the sector will be run more efficiently due to the inability of struggling services to stay viable. Indeed, the extension of the 20 hours ece to both community and private providers was ultimately rationalised as a means of extending consumer choice in the market and by extension allowing for a well-functioning market.

Despite how childcare markets should function theoretically, there are some fundamental problems to how it is assumed to work. As has been illustrated, parents are rarely aware of their childcare choices. Indeed, as Sarah Holloway (1998) has argued, childcare is sought out within situated childcare cultures, whereby what counts as legitimate care is shaped by the parental networks into which you are situated, rather than some autonomous decision making process on the part of the parent(s). Moreover, assuming parents can remove a child from a service as an active strategy in the market, overlooks the fundamental relational work at the heart of childcare. There is an emotional 
'stickyness' to childcare provisioning, based on the intersubjective and caring relationships which build between parent(s), child and carer (Boyer, et al., 2012), which means that changing services is often a last resort, rather than an active strategy in the market. For all these reasons, the very idea of a parent-consumer and the agency they are understood to now have, as imagined in policy, is fundamentally flawed. Moreover, the more recent trend towards corporatised childcare works further against the rationale of choice for the parent-consumer. While on the face of it there is a rise in the number of services available, the growth of corporate childcare over time significantly reduces the choice parents actually have (Brennan, 2007 ). If the same group is setting fees and providing services, albeit operating with a differentiated brand, then the ability of parents to 'shop around' is significantly diminished.

\section{Conclusion}

There has been a significant growth in childcare markets internationally, in line with the demand from mothers returning to work and incentivised through government subsidies into the sector. In New Zealand, the government ambition of reaching $98 \%$ participation coupled with the continued funding of the 20 hour ece scheme has stimulated significant growth in the sector. As demonstrated, this growth has taken place disproportionally in private sector care, with early evidence of a trend towards consolidation through childcare corporates. In the emergent market, parents are being reimagined as 'parent consumers', whose supposed ability to move between services serves to regulate the market in terms of cost and quality. However, as discussed in this paper, the concept of parental choice is highly questionable, particularly as the sector moves further toward reliance on a private sector which is consolidating under corporatized interests.

Ece is increasingly being viewed as a service which will address a range of social and economic policy issues in New Zealand (Haggerty \& Alcock, 2016). Aligning social policy ambitions alongside ece participation has led to the introduction of national student numbers and the close monitoring of children and families identified as being 'at risk'. Thus the discourse of choice frames the policy debates around ece as not one of whether or not to place your child in care, but rather what kind of service you place them in. Placing your child in ece (especially 3 and 4 year olds) is an increasing expectation, as illustrated through the $98 \%$ participation objective and through the recent changes to beneficiaries with children.

Lastly, it is important to consider how the childcare sector is changing in regard to how its performed and understood. The proliferation of specialised childcare industries (be it in finance or service management software) is a key aspect of the changing market. The expansion and consolidation of childcare services, a trend noted earlier in the paper, is being facilitated by the introduction of new cloud management software which is aiding providers and managers to record and comply with government regulations. These kinds of changes have tended to be absent from existing studies of childcare markets, however they represent a critical aspect in the changing daily performance of ece in New Zealand and elsewhere.

\section{$\underline{\text { References }}$}

Boyer, K., Reimer, S., \& Irvine, L. (2012). The nursery workspace, emotional labour, and contested understandings of commoditised childcare in the contemporary UK. Social and Cultural Geography, 1-24. 
Brennan, D. (2007). The ABC of childcare politics. Australian Journal of Social Issues, 42(2), 213-224.

Brennan, D., Cass, B., Himmelweit, S., \& Szebehely, M. (2012). The Marketisation of Care: Rationales and consequences in Nordic and liberal care regimes. Journal of European Social Policy, 22(4), 377-391. doi: 10.1177/0958928712449772

Beststart 2016, Why choose us? Retrieved from http://www.best-start.org/why-choose-us/who-isbeststart

Childforum. (2016, 2nd February). Big and Continuing Increase in Child Numbers at Centres. Retrieved from http://www.childforum.com/news-early-childhood-education-latest/1346child-number-early-childhood-education-centres.html

Clarke, J. (2004). Changing Welfare, Changing States: New Directions in Social Policy. London: Sage Publications.

Evolve Education (2016). Investment Statement. http://www.evolveeducation.co.nz/investorinformation

England, K. (1996). Who will mind the baby? : geographies of childcare and working mothers. London ; New York: Routledge.

Esping-Andersen, G. (1990). Three Worlds of Welfare Capitalism. Cambridge: Polity Press.

Esping-Andersen, G. (2002). Why We Need a New Welfare State. Oxford: Oxford University Press.

Gallagher, A. (2013). The Politics of Childcare Provisioning: A Geographical Perspective. Geography Compass, 7(2), 161-171. doi: 10.1111/gec3.12024

Green, M., \& Lawson, V. (2011). Recentring care: interrogating the commodification of care. Social \& Cultural Geography, 12(6), 639-654. doi: 10.1080/14649365.2011.601262

Group, W. W. (2011). Reducing Long-Term benefit Dependency: Recommendations. Wellington: Institute of Policy Studies, Victoria University.

Haggerty, M., \& Alcock, S. (2016). The changing roles of early childhood care and education in Aotearoa New Zealand: A shifting policy landscape. Global Studies of Childhood, 6(1), 136146. doi: $10.1177 / 2043610615625164$

Halliday, J., \& Little, J. (2001). Amongst women: Exploring the reality of rural childcare. Sociologia Ruralis, 41(4), 423-+.

Herald, T. N. Z. (2009, 27th April). Unravelling Company Accounts not as easy as ABC, The New Zealand Herald.

Holloway, S. L. (1998). Local Childcare Cultures: moral geographies of mothering and the social organisation of pre-school education. Gender, Place and Culture - A Journal of Feminist Geography, 5, 29-53.

Holloway, S. L., \& Pimlott-Wilson, H. (2016). New economy, neoliberal state and professionalised parenting: mothers' labour market engagement and state support for social reproduction in class-differentiated Britain. Transactions of the Institute of British Geographers, n/a-n/a. doi: 10.1111/tran.12130

Jenson, J., \& Saint-Martin, D. (2003). New routes to social cohesion? Citizenship and the social investment state. Canadian Journal of Sociology-Cahiers Canadiens De Sociologie, 28(1), 7799.

Jones, N., \& Johnston, K. (2016, 15th March ). Schools Shake-Up: No more deciles?, The New Zealand Herald.

Kingfisher, C., P. (2013). A Policy Travelogue: Tracing Welfare Reform in Aotearoa/New Zealand and Canada. New York: Berghahn Books.

Kruger, C. (2011). Numbers Finally Start to Add Up as Operators go Back to Business, The Sydney Morning Herald.

Lee, W., Carr, M., Soutar, B., \& Mitchell, B. (2012). Understanding the Te Whariki Approach. London: Routledge.

Lloyd, E. (2013). Childcare Markets: An Introduction. In E. Lloyd \& H. Penn (Eds.), Childcare Markets: Can they deliver equitable service? (pp. 3-18). Bristol: Policy Press. 
Lloyd, E., \& Penn, H. (Eds.). (2013). Childcare Markets: Can they deliver an equitable service? Bristol: Policy Press.

Mahon, R., \& Michel, S. (2002). Childcare Policy at the Crossroads: gender and Welfare State Restructuring. London: Routledge Publications.

May, H. (2013). The Changing Fortunes of Childcare 2003-2013

May, H., \& Mitchell, L. (2009). Report on the Quality Public Early Childhood Education (QPECE) Project 2009. Wellington.

McDowell, L., Ray, K., Perrons, D., Fagan, C., \& Ward, K. (2005). Women's paid work and moral economies of care. Social \& Cultural Geography, 6(2), 219-235.

Mitchell, L. (2013). Markets and Childcare in New Zealand: Towards a fairer alternative. In E. Lloyd \& H. Penn (Eds.), Childcare Markets: Can they deliver an equitable service? (pp. 97-114). Bristol: Policy Press.

Mitchell, L. (2015). Shifting Directions in ECEC Policy in New Zealand: From a Child Rights to an Interventionist Approach. International Journal of Early Years Education, 23(3), 1-15.

Mitchell, L., Meagher-Lundberg, P., Taylor, M., Caulcutt, T., Kalavite, T., Kara, H., \& Paki, V. (2013). ECE Participation Programme Evaluation In M. o. Education (Ed.).

Ministry of Education,. (2016). Participation in Early Childhood Education.

Ministry of Social Development., (2012). White Paper for Vulnerable Children. Wellington.

Newbury, S., \& Brennan, D. (2013). The marketisation of early childhood education and care (ECEC) in Australia: A structured response. Financial Accountability and Management, 29(3), 227245.

New Zealand Government. (2011). Better Public Services Advisory Report.

Osgood, J. (2004). Time to Get Down to Business? Journal of Early Childhood Research, 2(1), 5-24. doi: $10.1177 / 1476718 \times 0421001$

Owen, H. (2007, 6th July). Kidicorp Chief Keen to Shed Shareholders, The New Zealand Herald.

Penn, H. (2011). Gambling on the market: The role of for-profit provision in early childhood education and care. Journal of Early Childhood Research, 9(2), 150-161. doi: $10.1177 / 1476718 \times 10387999$

Plantenga, J. (2012a). Local providers and loyal parents: Competition and consumer choice in the Dutch childcare market. In E. Lloyd \& H. Penn (Eds.), Childcare markets: Can they deliver an equitable service? (pp. 63-78). Bristol: Policy Press.

Plantenga, J. (2012b). A Market for Childcare Services? Private Provision and Public Finance in the Dutch Childcare Sector. In G. Mayes \& M. Thompson (Eds.), The Costs of Children: Parenting and Democracy in Comtemporary Europe (pp. 92-107). Cheltenham: Edward Elgar Publishing.

Powley, K. (2013, 3rd March). Kiwi Families Conned by promise of 'Free' Childcare, The New Zealand Herald. Retrieved from http://www.nzherald.co.nz/nz/news/article.cfm?c_id=1\&objectid=10868835

Pratt, G. (2003). Valuing Childcare: Troubles in Suburbia. Antipode, 35(3), 581-602.

Scherer, K. (2009, 27th April). Little People, Big Money, The New Zealand Herald.

Sumsion, J. (2006). The corporatization of Australian childcare: Towards an ethical audit and research agenda. Journal of Early Childhood Research, 4(2), 99-120. doi: $10.1177 / 1476718 \times 06063531$

Van Ham, M., \& Mulder, C. (2005). Geographical access to childcare and mothers' labour-force participation. Tijdschrift voor Economische en Sociale Geografie. 
'Early Childhood Education and Care (ECE) refers to services which have met the expectations around teacher training in order to provide an educational environment to the young children. Most services in NZ now are ECE services since the 20 hours ece scheme. However, childcare is also used as a broader term, one which also captures services which do not meet the educational requirements (although this does not mean that they are not educational in their work). From a policy perspective, childcare has tended to be the term invoked in employment debates (relating to mothers returning to work) whereas ECE is most often used in educational policy, highlighting the conflicting messages and understandings of the field by policy makers.

ii In this paper I am referring to only formalised childcare, but acknowledge that there is also a significant informal sector. Indeed, NZ has one of the highest rates of families using more than one form of childcare, which often extends into the informal sector (Mitchell 2013).

iii The minimum expectation is $50 \%$ teacher training, but they have agreed to fund up to $80 \%$ teacher led services. This is still a significant target in relation to the qualification rates of early education teachers in other countries.

iv The term 'free' was removed from the title by Minister Anne Tolley in 2009, signaling a significant change in how education and care was perceived by the incoming National government.

${ }^{v}$ TAPS funding was $13 \$$ million in 2015-2016. Priority areas identified in this funding round have been primarily in South and West Auckland, Northland and parts of Taranaki.

${ }^{v i}$ All efforts have been made to ensure this data is interpreted correctly. There are some absences in the datasets, but this is the most accurate information available at this point.

vii Data is missing for the West Coast in the 2006 directory 


\title{
Growing pains? Change in the New
}

Zealand childcare market 2006-2016

\author{
Gallagher, A
}

2017-04

22/04/2023 - Downloaded from MASSEY RESEARCH ONLINE 